\title{
POSITIVE DEFINITE SOLUTIONS OF CERTAIN NONLINEAR MATRIX EQUATIONS
}

\author{
Z. Mousavi, F. Mirzapour and M. S. Moslehian
}

Abstract. We investigate positive definite solutions of nonlinear matrix equations $X-f(\Phi(X))=$ $Q$ and $X-\sum_{i=1}^{m} f\left(\Phi_{i}(X)\right)=Q$, where $Q$ is a positive definite matrix, $\Phi$ and $\Phi_{i}(1 \leqslant i \leqslant m)$ are positive linear maps on $\mathbb{M}_{n}(\mathbb{C})$ and $f$ is a nonnegative matrix monotone or matrix antimonotone function on $[0, \infty)$. In this article, using appropriate inequalities and some fixed point results, we prove the existence of unique positive definite solutions for the mentioned above equations.

Mathematics subject classification (2010): 15A24.

Keywords and phrases: Nonlinear matrix equation, matrix monotone, positive definite solution, positive linear map.

\section{REFERENCES}

[1] W. N. Anderson, JR., T. D. Morley And G. E. Trapp, Positive solutions to $X=A-B X^{-1} B^{*}$, Linear Algebra Appl. 134 (1990), 53-62.

[2] R. Bhatia, Matrix Analysis, Grad. Texts in Math. 169, Springer-Verlag, New York, 1997.

[3] D. A. Bini, G. Latoucheb And B. Meini, Solving nonlinear matrix equations arising in Tree-Like stochastic processes, Linear Algebra Appl. 366 (2003), 39-64.

[4] X. Duan And A. Liao, On the nonlinear matrix equation $X+A^{*} X^{-q} A=Q(q \geqslant 1)$, Math. Comput. Modelling 49 (2009), 936-945.

[5] X. DUAN AND A. LiAO, On Hermitian positive definite solution of the matrix equation $X-$ $\sum_{i=1}^{m} A_{i}^{*} X^{r} A_{i}=Q$, J. Comput Appl. Math. 229 (2009), no. 1, 27-36.

[6] X. DuAn, A. Liao And B. TANG, On the nonlinear matrix equation $X-\sum_{i=1}^{m} A_{i}^{*} X^{\delta_{i}} A_{i}=Q$, Linear Algebra Appl. 429 (2008), 110-121.

[7] S. M. EL-SAYED AND A. C. M. RAN, On an iteration method for solving a class of nonlinear matrix equations, Siam J. Matrix Anal. Appl. 23 (2001), no. 3, 632-645.

[8] J. C. Engwerda, A. C. M. Ran And A. L. Rijkeboer, Necessary and sufficient conditions for the existence of a positive definite solution of the matrix equation $X+A^{*} X^{-1} A=Q$, Linear Algebra Appl. 186 (1993), 255-275.

[9] F. O. Farid, M. S. Moslehian, Q.-W. Wang And Z.-C. Wu, On the Hermitian solutions to a system of adjointable operator equations, Linear Algebra Appl. 437 (2012), no. 7, 1854-1891.

[10] A. GRanas And J. Dugundu, Fixed Point Theory, Springer-verlag, New York, 2003.

[11] D. GUO, Nonlinear functional analysis, Shangdong Sci. and Tech. press, Jinan, 2001.

[12] V. HASANOV AND I. IVANOV, Solutions and perturbation estimates for the matrix equations $X \pm$ $A^{*} X^{-n} A=I$, Appl. Math. Comput. 156 (2004), 513-525.

[13] I. G. IVAnOV, V. I. HAS ANOV AND F. Uhlig, Improved methods and starting values to solve the matrix equations $X \pm A^{*} X^{-1} A=I$ iterativly, Math. Comput. 74 (2004), 263-278.

[14] F. Kubo And T. Ando, Means of positive linear operators, Math. Ann. 246 (1980), $205-224$.

[15] B. C. Levy, R. Frezza And A. J. Krener, Modeling and estimation of discretetime Gaussian reciprocal processes, IEEE Trans. Automat. Control 35 (1990), 1011-1023.

[16] Y. D. LIM, Solving the nonlinear matrix equation $X=Q+\sum_{i=1}^{m} m_{i} X^{\delta_{i}} M_{i}^{*}$ via a contraction principle, Linear Algebra Appl. 430 (2009), 1380-1383. 
[17] B. Meini, Nonlinear matrix equations and structured linear algebra, Linear Algebra Appl. 413 (2006), 440-457.

[18] J. PeČARIĆ, T. Furuta, J. M. Hot And Y. SEO, Mond-Pečarić method in operator inequalities, Element, Zagreb, 2005.

[19] A. C. M. RAn And M. C. B. Reurings, On the nonlinear matrix equation $X-A^{*} f(X) A=Q$ : solutions and perturbation theory, Linear Algebra Appl. 346 (2002), 15-26.

[20] A. C. M. RAN AND M. C. B. ReuringS, A nonlinear matrix equation connected to interpolation theory, Linear Algebra Appl. 379 (2004), 289-302.

[21] A. C. M. RAN, M. C. B. Reurings AND L. Rodman, A perturbation analysis for nonlinear selfadjoint operator equations, SIAM J. Matrix Anal. Appl. 28 (2006), no. 1, 89-104.

[22] M. C. B. Reurings, Contractive maps on normed linear spaces and their applications to nonlinear matrix equations, Linear Algebra Appl. 418 (2006), 292-311. 